\title{
Unilateral optic disc swelling as a first sign of optic nerve sheath meningioma a case report
}

\author{
Agnieszka Kiszka, Katarzyna Nowomiejska, Robert Rejdak \\ Department of General Ophthalmology, Medical University of Lublin, Poland
}

\begin{abstract}
Optic nerve sheath meningiomas (ONSM) are rare, slow-growing, benign tumours, which constitute approximately $2 \%$ of all orbital tumours of the anterior visual pathway (or orbital or anterior visual pathway) and $1-2 \%$ of all meningiomas. Middle-aged females are primarily affected. Untreated ONSMs usually lead to progressive visual decline, colour blindness, and finally complete loss of vision. Surgical excision may result in blindness in the affected eye. Stereotactic fractionated radiotherapy has recently shown effectiveness in improving or stabilising remaining visual function with minimal procedural morbidity in patients with ONSM. We present a case of a 59-year-old female with unilateral optic nerve sheath meningioma treated with stereotactic fractionated radiotherapy. During eight months of follow-up we observed persistent oedema of the right optic disc and full visual acuity. Optical coherence tomography showed decreased peripapillary nerve fibre layer.
\end{abstract}

KEY WORDS: meningioma, optic nerve, optic nerve sheath meningiomas, orbital tumour

Ophthalmol J 2017; Vol. 2, No. 4, 117-123

\section{INTRODUCTION}

Tumours of the optic nerve represent approximately $4 \%$ of orbital tumours and can occur at any age $[1,2]$. Although uncommon tumours such as haemangiopericytomas and medulloepitheliomas are occasionally reported, the majority are either optic nerve gliomas or optic nerve sheath meningiomas (ONSMs). While gliomas usually occur in children, most ONSMs are slow-growing tumours affecting middle-aged persons. Typically, ONSM affects middle-aged women with an average age of 41 years [3]. These lesions can arise primarily from the optic nerve sheath or may involve the optic nerve secondarily after arising from the cavernous sinus, falciform ligament, sphenoid wing, pituitary fossa, planum sphenoidale, frontoparietal area, or the olfactory groove. Progressive visual loss, optic nerve atrophy, and presence of optociliary collateral vessels, known as the Hoyt-Spencer triad, are a classic sign of an ONSM [4]. The most common visual field defect is peripheral constriction, although other field defects such as blind spot enlargement, altitudinal field defects, and central scotomas have been described $[1,3,5]$. The diagnosis of ONSM is usually made on the basis of clinical and radiographic findings [6]. Meningiomas typically display intense homogenous enhancement with gadolinium-enhanced fat-suppression T1-weighted pulse sequences in magnetic resonance imaging (MRI) [7]. Definitive treatment of ONSMs is challenging, however, because of the lesions' intimate circumferential relationship with the optic nerve and its vascular supply. Surgical excision has almost always resulted in postoperative blindness in the affected eye $[1,8,9,10]$. Many believe that patients with optic nerve sheath meningioma (ONSM) can be 
observed if there is no evidence of intracranial extension and if there is mild or no vision loss or, in some cases, stable degrees of vision loss [11].

\section{CASE REPORT}

A 59-year-old female presented to our department due to the right-sided optic disc oedema. The oedema was detected accidentally during routine testing. Before the visit in our clinic the patient underwent neurological consultation. Neurological examination was unremarkable. The initial CT of the brain did not show any abnormalities. On examination, visual acuity was 1.0 without correction in both eyes. The pupils were symmetric, properly reactive, absolute afferent papillary defect was observed. Anterior segment examination under the slit-lamp was within normal limits. The fundus examination revealed optic disc oedema in the right eye and normal findings in the left eye. Static automated perimetry (Octopus 900) was performed and showed non-specific defects in the visual field of the right eye (Fig. 1). Optical coherence tomography (OCT) showed decreased peripapillary nerve fibre layer (RNFL) in the right eye (Fig. 2), without abnormalities in the macular scans (Fig. 3). Laboratory tests for Lyme disease and toxoplasmosis were negative. The diagnosis of anterior ischaemic optic neuropathy (AION) was made. Because after two months of observation optic disc oedema was still present, MRI of the brain and orbit with contrast enhancement was performed. It showed an abnor$\mathrm{mal}$ area along the entire intra-orbital segment of the right optic nerve, about $3 \mathrm{~cm}$ long, hyperintensive after intravenous administration of contrast, causing compression of the right optic nerve and its thinning (Fig. 4). The tumour had no intracranial extension along the optic nerve. A diagnosis of optic nerve sheath meningioma was made. Additionally, an MRI of the brain showed pathology in the left bridge-cerebellum angle, measuring approximately $7.0 \times 4.0 \mathrm{~mm}$, without affecting the brainstem. The presence of meningioma was assumed. As a treatment, radiotherapy was advised by the radiation therapist. The patient underwent radiotherapy of the right optic nerve sheath meningioma with a margin-dose per fraction $1.8 \mathrm{~Gy}$, up to total dose of 50.4 Gy with anti-swelling treatment (Dexamethasone).

In our eight-month observation the tumour did not show progression and the vision remained unchanged. The optic disc oedema did not resolve, but the visual acuity was still full. Optical coherence tomography (OCT) still showed decreased peripapillary nerve fibre layer (RNFL) in the right eye (Fig. 5).

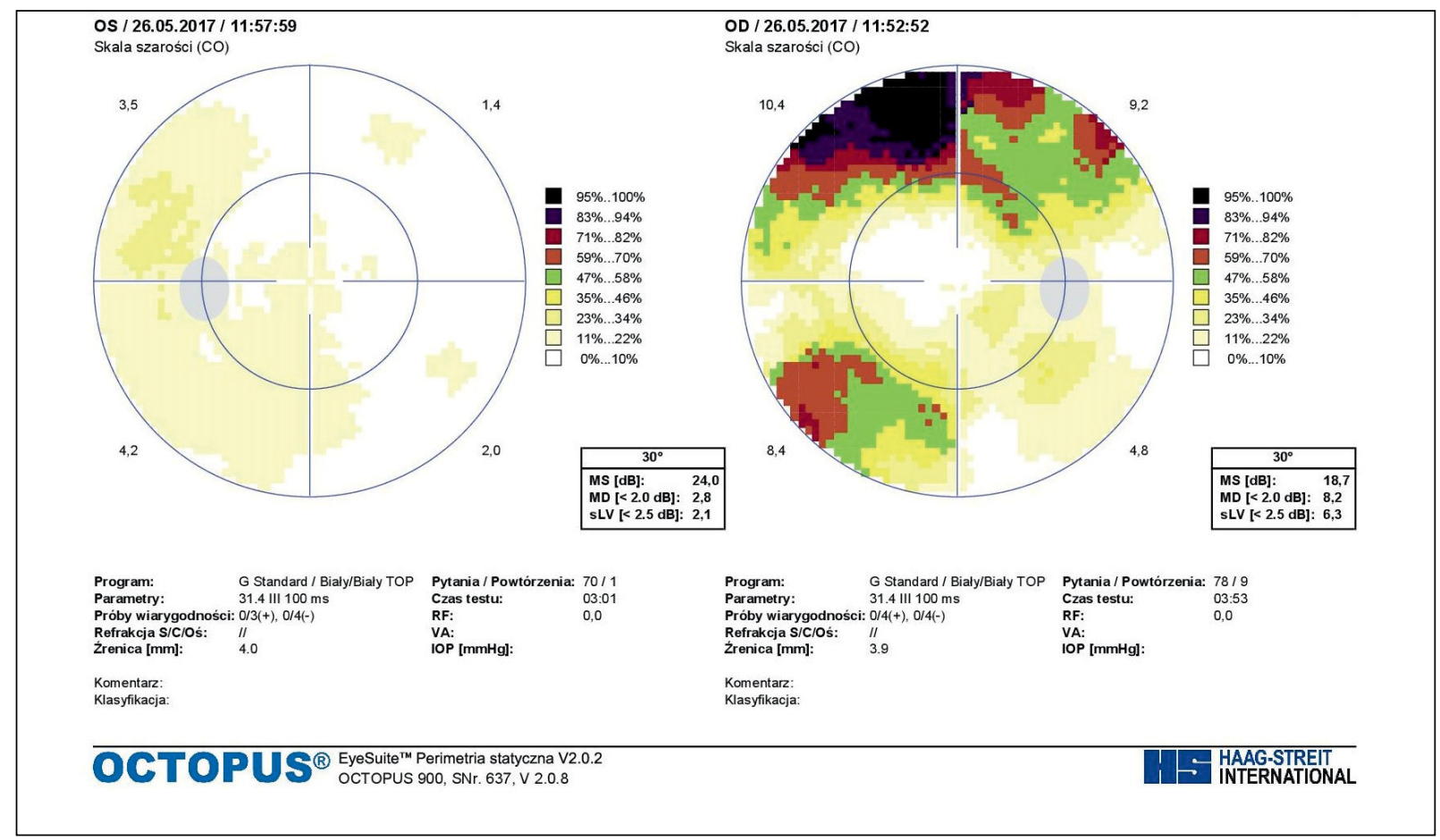

FIGURE 1. Static automated perimetry (Octopus 900): non-specific defects in the visual field of the right eye 


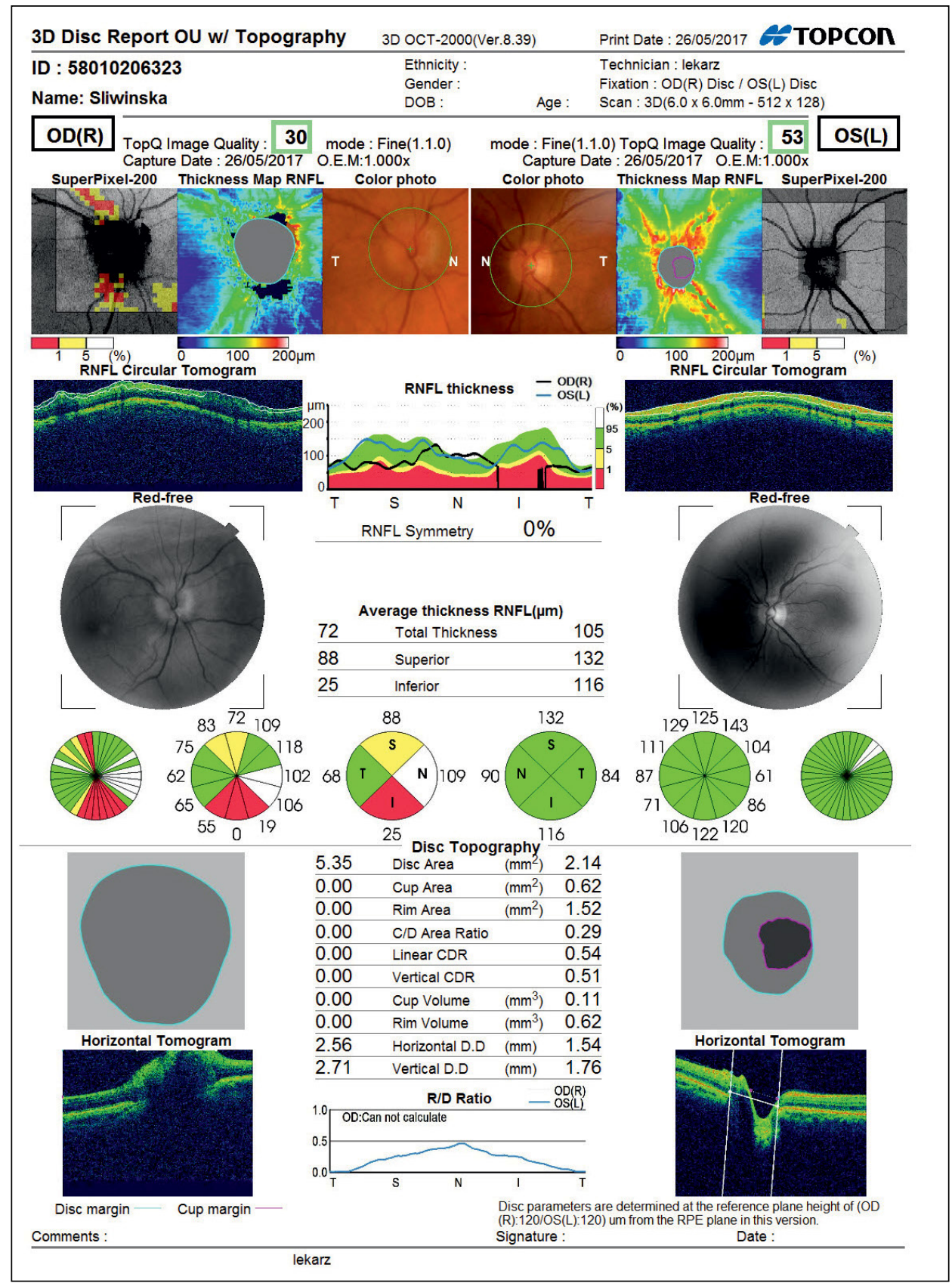

FIGURE 2. Optical coherence tomography (OCT) — decreased peripapillary nerve fibre layer (RNFL) in the right eye

\section{DISCUSSION}

ONSMs are rare tumours of the anterior visual pathway [1]. Primary ONSMs arise from meningo-epithelial cap cells of the arachnoid villi and can develop at any location along the entire course of the optic nerve sheath $[1,10]$. Secondary ONSMs may arise from tissues outside the orbit, namely the cavernous sinus, falciform ligament, clinoid processes, sphenoid wing, pituitary fossa, planum sphenoidale, tuberculum sellae, frontotemporal dura, and/or olfactory groove, and may secondarily grow into the optic nerve sheath. The mean age at presentation of ONSM patients is 40.8 years ( 42.5 years in women and 36.1 years in men; range $3-80$ years), with $61 \%$ of the patient population being females [1]. Approximately $4-7 \%$ of ONSMs occur in patients below 20 years of age. Unlike adult ONSM patients, there is no gender preference in children with ONSMs, and in the paediatric population the lesions are often associated with neurofibromatosis type $2[1,8]$. Furthermore, ONSMs in paediatric patients are frequently more aggressive, are associ- 


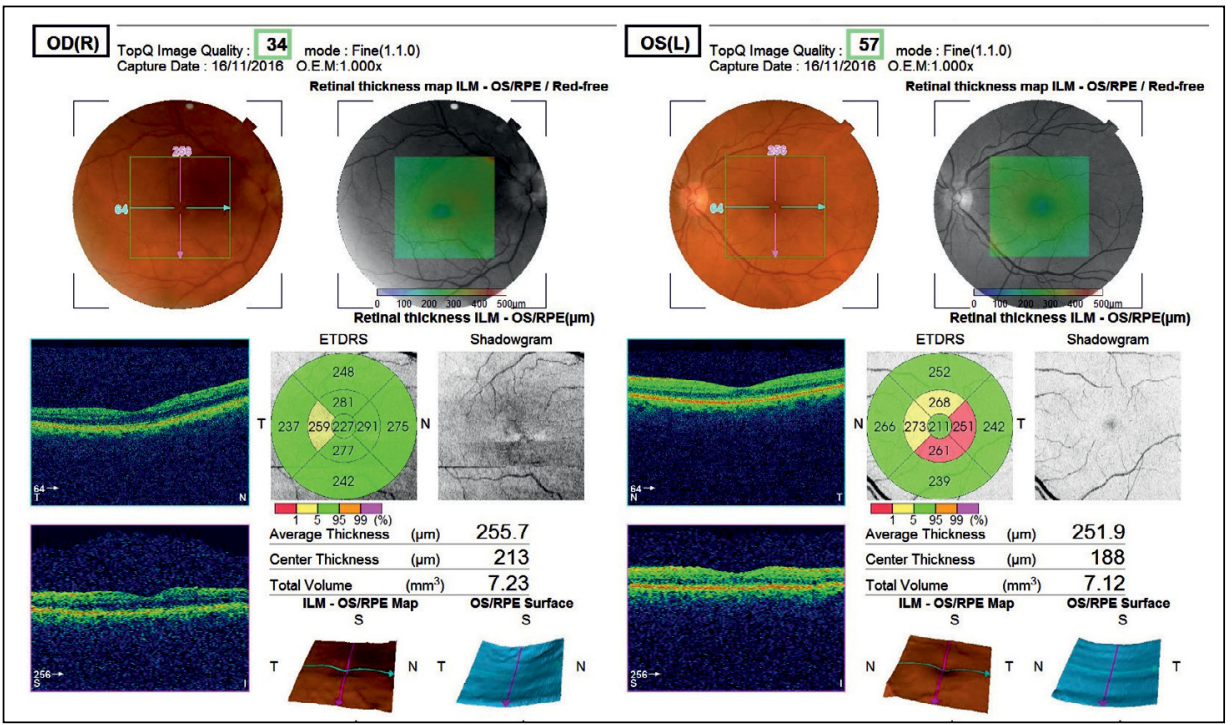

FIGURE 3. OCT macular scans without abnormalities

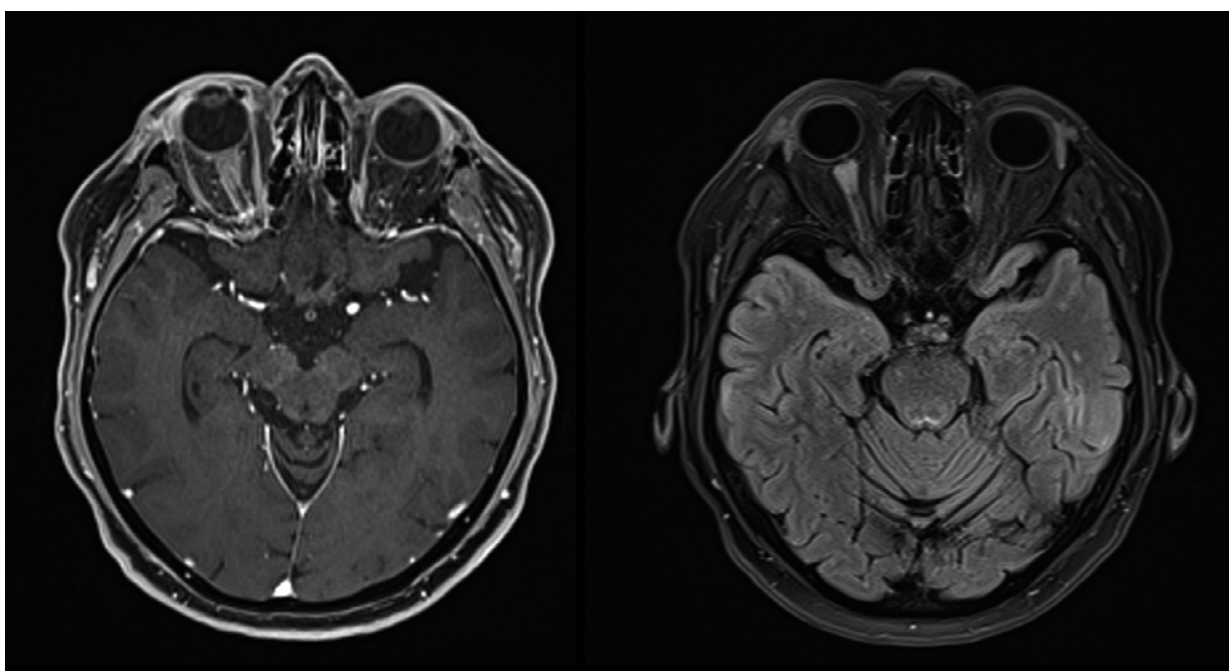

FIGURE 4. MRI of the brain and orbit — optic nerve sheath meningioma of the right eye

ated with higher rates of intracranial extension on presentation, have a higher rate of bilateral presentation, and have higher rates of recurrence $[1,8$, $10]$. Only $5 \%$ of ONSMs present bilaterally, and $65 \%$ of these bilateral lesions are intracanalicular $[1,10]$. About half of the patients who present with bilateral ONSMs also have tumours along the planum sphenoidale in continuity with these lesions, a finding that raises questions about the true origin of bilateral ONSMs. Bilateral and multifocal presentations of ONSMs are most commonly found in patients with neurofibromatosis type $2[1,8,10]$. The classic triad of optic atrophy, visual loss, and the presence of optociliary shunt vessels is pathog- nomonic for the clinical presentation of ONSMs; however, this is present in only a minority of patients $[8,10,12,13]$. The most common presenting symptom in patients with ONSMs (present in approximately $96 \%$ of cases) is painless, progressive loss of visual acuity or visual field, with progression often lasting $1-5$ years before presentation $[8,10$, $12,13]$. Commonly reported clinical manifestations of ONSM include ipsilateral visual loss, afferent pupillary defect, colour vision disturbance, visual field defect, proptosis, optic disc oedema, motility disturbance, pain, and lower eyelid oedema [14]. Patients have symptoms of gradual or rapid visual loss, diplopia, or gaze-evoked visual obscurations 


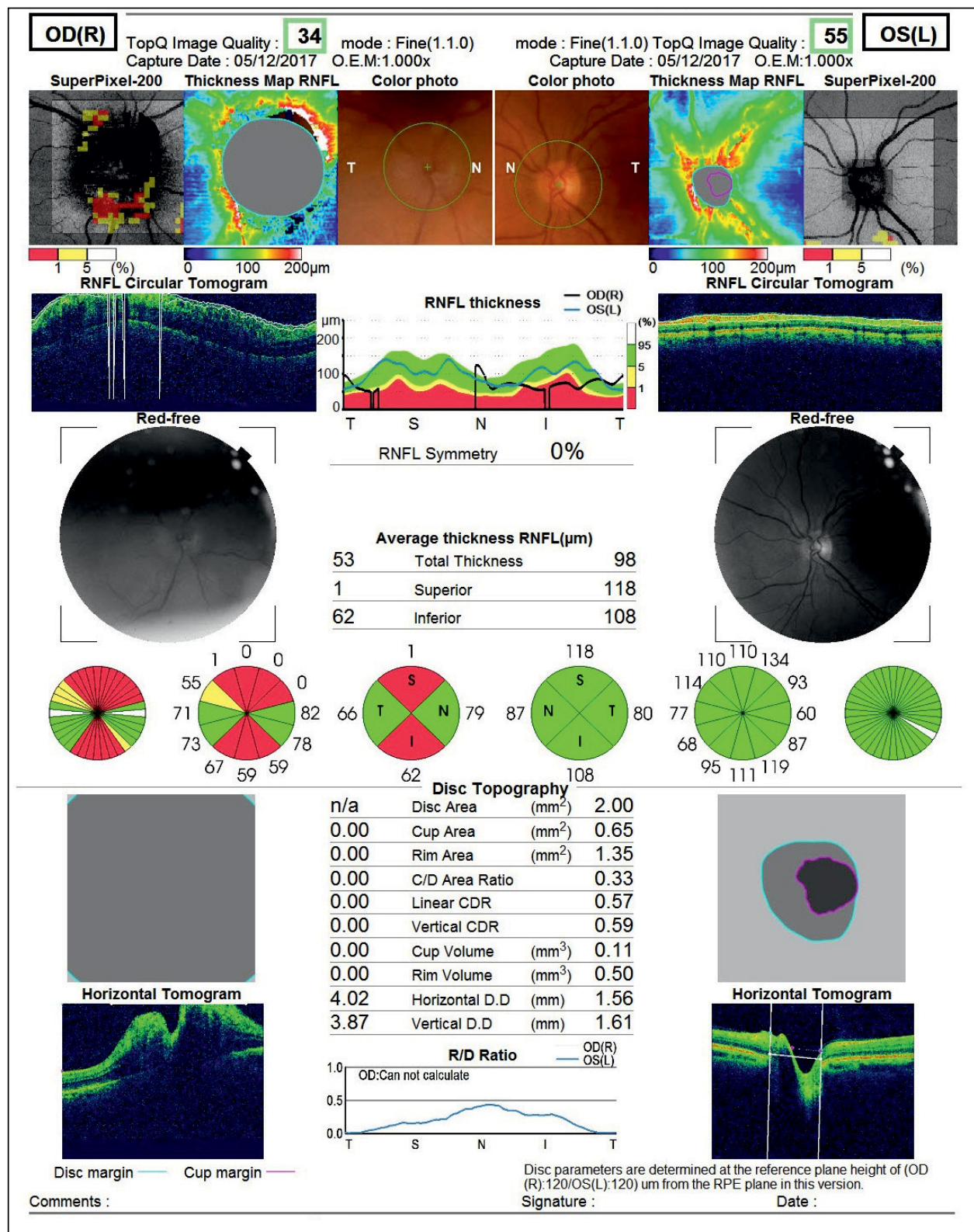

FIGURE 5. Optical coherence tomography (OCT) after 8 months of observation — decreased peripapillary nerve fibre layer (RNFL) in the right eye

$[1,13,15]$. Ophthalmoscopic examination may reveal optic nerve head swelling, contiguous macular oedema, nerve pallor, or choroidal folds. Optic disc swelling, accompanied by optic nerve pallor, may also be observed, as in our case. As visual function declines, the optic disc oedema may resolve, leaving a pale nerve head. The optic disc may be pale, with no prior swelling observed, when the meningioma is at the apex or within the optic canal [16]. However, posterior lesions may also present with optic disc swelling [17]. In our case, visual acuity was full during the follow-up. Other nonspecific complaints may include orbital pain and headaches, which have been reported in $2-50 \%$ of patients with ONSM $[8,10,12,13]$. The gold standard for visualisation of ONSMs is MRI $[18,19]$. Although CT allows visualisation of the tumour, only MR imaging (especially with post-gadolinium fat-suppression sequences) can significantly delineate the optic nerve as it courses through the optic canal [18, 19]. Early detection of ONSM is essential to initiate early intervention and prevent subsequent growth into the intracranial cavity. Like intracranial meningiomas, ONSMs are contrast-enhancing lesions. The classic imaging "tram-tracking" sign can be easily visualised and consists of the thickened optic 
nerve sheath containing the lesion surrounding the non-enhancing, radiolucent optic nerve $[18,19]$. This thickened optic nerve can appear as a calcified nerve sheath on CT images. On coronal views, the tumour demonstrates a doughnut shape, with the dense nerve sheath tumour encircling the optic nerve. Several imaging patterns of ONSM growth have been observed, namely tubular (diffuse, apical expansion, anterior expansion), globular, fusiform, and focal $[10,18,19]$. Definitive treatment of ONSMs is challenging because of the lesion's intimate circumferential relationship with the optic nerve and its vascular supply. Surgical excision has almost always resulted in postoperative blindness in the affected eye $[1,8,9,10]$. Conservative management is indicated if there is no significant progressive visual dysfunction or intracranial extension of the tumour. Recently, it has been highlighted by Miller that surgery to remove an ONSM is rarely, if ever, indicated, and radiation is the optimum therapy [11]. Radiotherapy, both conventional and stereotactic, has been shown to have good efficacy, with local tumour control and stabilisation or improvement in visual function, and has been recommended as the best option for most cases of progressive or advanced disease $[1,8,10,12,20-36]$. Despite the positive results reported in the literature, concerns regarding complications secondary to radiation-induced effects have limited the overall acceptance of radiotherapy.

\section{CONCLUSIONS}

In cases of unilateral disc oedema, ONSM should be considered as one of the differential diagnoses. In cases of optic nerve sheath meningioma (ONSM), a team approach involving ophthalmologists, neurologists, neurosurgeons, radiation therapists, and radiologists is the most beneficial.

\section{REFERENCES}

1. Dutton JJ. Optic nerve sheath meningiomas. Surv Ophthalmol. 1992; 37(3): 167-183, doi: 10.1016/0039-6257(92)90135-g, indexed in Pubmed: 1475751.

2. Imes RK, Schatz H, Hoyt WF, et al. Evolution of optociliary veins in optic nerve sheath meningioma. Evolution. Arch Ophthalmol. 1985; 103(1): 59-60, doi: 10.1001/archopht.1985.01050010063020, indexed in Pubmed: 3977677.

3. Saeed $P$, Blank L, Selva D, et al. Optic nerve sheath meningiomas. Ophthalmology. 2003; 110(10): 2019-2030, doi: 10.1016/S01616420(03)00787-5, indexed in Pubmed: 14522782.

4. Miller NR. Primary tumours of the optic nerve and its sheath. Eye (Lond). 2004; 18(11): 1026-1037, doi: 10.1038/sj.eye.6701592, indexed in Pubmed: 15534587.

5. Kim JW, Rizzo JF, Lessell S. Controversies in the management of optic nerve sheath meningiomas. Int Ophthalmol Clin. 2005; 45(4):
15-23, doi: 10.1097/01.iio.0000176367.16758.f4, indexed in Pubmed: 16199964.

6. Eddleman CS, Liu JK. Optic nerve sheath meningioma: current diagnosis and treatment. Neurosurg Focus. 2007; 23(5): E4, doi: 10.3171/ FOC-07/11/E4, indexed in Pubmed: 18004966.

7. Mafee MF, Goodwin J, Dorodi S. Optic nerve sheath meningiomas. Role of MR imaging. Radiol Clin North Am. 1999; 37(1): 37-58, ix, doi: 10.1016/s0033-8389(05)70077-4, indexed in Pubmed: 10026728.

8. Berman D, Miller NR. New concepts in the management of optic nerve sheath meningiomas. Ann Acad Med Singapore. 2006; 35(3): 168-174, indexed in Pubmed: 16625265.

9. Alper MG. Management of primary optic nerve meningiomas. Current status--therapy in controversy. J Clin Neuroophthalmol. 1981; 1(2): 101-117, indexed in Pubmed: 6213649.

10. Carrasco JR, Penne RB. Optic nerve sheath meningiomas and advanced treatment options. Curr Opin Ophthalmol. 2004; 15(5): 406-410, doi: 10.1097/01.icu.0000138617.53435.d9, indexed in Pubmed: 15625901.

11. Miller NR. New concepts in the diagnosis and management of optic nerve sheath meningioma. J Neuroophthalmol. 2006; 26(3): 200-208, doi: 10.1097/01.wno.0000235569.19131.ac, indexed in Pubmed: 16966942.

12. Liu JK, Forman S, Moorthy CR, et al. Update on treatment modalities for optic nerve sheath meningiomas. Neurosurg Focus. 2003; 14(5): e7, doi: 10.3171/foc.2003.14.5.8, indexed in Pubmed: 15669818.

13. Sibony PA, Krauss HR, Kennerdell JS, et al. Optic nerve sheath meningiomas. Clinical manifestations. Ophthalmology. 1984; 91(11): 1313-1326, indexed in Pubmed: 6514296.

14. Wright JE. Primary optic nerve meningiomas: clinical presentation and management. Trans Sect Ophthalmol Am Acad Ophthalmol Otolaryngol. 1977; 83(4 Pt 1): 617-625, indexed in Pubmed: 898481.

15. Cameron EW. Transient ischaemic attacks due to meningioma--report of 4 cases. Clin Radiol. 1994; 49(6): 416-418, doi: 10.1016/s00099260(05)81829-x, indexed in Pubmed: 8045068.

16. Knight CL, Hoyt WF, Wilson CB. Syndrome of incipient prechiasmal optic nerve compression. Progress toward early diagnosis and surgical management. Arch Ophthalmol. 1972; 87(1): 1-11, doi: 10.1001/ archopht.1972.01000020003001, indexed in Pubmed: 4332497.

17. Kennerdell JS, Maroon JC. Intracanalicular meningioma with chronic optic disc edema. Ann Ophthalmol. 1975; 7(4): 507-512, indexed in Pubmed: 1147497.

18. Lindblom B, Truwit CL, Hoyt WF. Optic nerve sheath meningioma. Definition of intraorbital, intracanalicular, and intracranial components with magnetic resonance imaging. Ophthalmology. 1992; 99(4): 560-566, doi: 10.1016/s0161-6420(92)31932-3, indexed in Pubmed: 1584575.

19. Turbin RE, Pokorny K. Diagnosis and treatment of orbital optic nerve sheath meningioma. Cancer Control. 2004; 11(5): 334-341, doi: 10.1177/107327480401100508, indexed in Pubmed: 15377993.

20. Andrews DW, Faroozan R, Yang BP, et al. Fractionated stereotactic radiotherapy for the treatment of optic nerve sheath meningiomas: preliminary observations of 33 optic nerves in 30 patients with historical comparison to observation with or without prior surgery. Neurosurgery. 2002; 51(4): 890-902; discussion 903, doi: 10.1227/00006123200210000-00007, indexed in Pubmed: 12234395.

21. Baumert BG, Villà S, Studer G, et al. Early improvements in vision after fractionated stereotactic radiotherapy for primary optic nerve sheath meningioma. Radiother Oncol. 2004; 72(2): 169-174, doi: 10.1016/j. radonc.2004.04.008, indexed in Pubmed: 15297135.

22. Becker G, Jeremic B, Pitz S, et al. Stereotactic fractionated radiotherapy in patients with optic nerve sheath meningioma. Int $J$ Radiat Oncol Biol Phys. 2002; 54(5): 1422-1429, doi: 10.1016/ s0360-3016(02)03753-7.

23. Capo H, Kupersmith MJ. Efficacy and complications of radiotherapy of anterior visual pathway tumors. Neurol Clin. 1991; 9(1): 179-203, indexed in Pubmed: 2011109.

24. Eng TY, Albright NW, Kuwahara G, et al. Precision radiation therapy for optic nerve sheath meningiomas. Int J Radiat Oncol Biol Phys. 1992; 22(5): 1093-1098, doi: 10.1016/0360-3016(92)90814-x, indexed in Pubmed: 1555959. 
25. Jeremic $B$, Pitz S. Primary optic nerve sheath meningioma: stereotactic fractionated radiation therapy as an emerging treatment of choice. Cancer. 2007; 110(4): 714-722, doi: 10.1002/cncr.22859, indexed in Pubmed: 17582618.

26. Klink DF, Miller NR, Williams J. Preservation of residual vision 2 years after stereotactic radiosurgery for a presumed optic nerve sheath meningioma. J Neuroophthalmol. 1998; 18(2): 117-120, doi: 10.1097/00041327-199806000-00009, indexed in Pubmed: 9621268.

27. Landert M, Baumert BG, Bosch MM, et al. The visual impact of fractionated stereotactic conformal radiotherapy on seven eyes with optic nerve sheath meningiomas. J Neuroophthalmol. 2005; 25(2): 86-91, doi: 10.1097/01.wno.0000165105.78365.22, indexed in Pubmed: 15937428.

28. Lee AG, Woo SY, Miller NR, et al. Improvement in visual function in an eye with a presumed optic nerve sheath meningioma after treatment with three-dimensional conformal radiation therapy. J Neuroophthalmol. 1996; 16(4): 247-251, doi: 10.1097/00041327-19961200000004, indexed in Pubmed: 8956159.

29. Liu JK, Forman S, Hershewe GL, et al. Optic nerve sheath meningiomas: visual improvement after stereotactic radiotherapy. Neurosurgery. 2002; 50(5): 950-957, doi: 10.1227/00006123-20020500000006, indexed in Pubmed: 11950397.

30. Moyer PD, Golnik KC, Breneman J. Treatment of optic nerve sheath meningioma with three-dimensional conformal radiation. Am J Ophthal- mol. 2000; 129(5): 694-696, doi: 10.1016/s0002-9394(99)00477-8, indexed in Pubmed: 10844079.

31. Pitz S, Becker G, Schiefer U, et al. Stereotactic fractionated irradiation of optic nerve sheath meningioma: a new treatment alternative. $\mathrm{Br} J$ Ophthalmol. 2002; 86(11): 1265-1268, doi: 10.1136/bjo.86.11.1265, indexed in Pubmed: 12386086.

32. Richards JC, Roden D, Harper CS. Management of sight-threatening optic nerve sheath meningioma with fractionated stereotactic radiotherapy. Clin Exp Ophthalmol. 2005; 33(2): 137-141, doi: 10.1111/j.1442-9071.2005.00973.x, indexed in Pubmed: 15807820.

33. Shrieve DC, Tarbell NJ, Alexander E, et al. Stereotactic radiotherapy: a technique for dose optimization and escalation for intracranial tumors. Acta Neurochir Suppl. 1994; 62: 118-123, doi: 10.1007/978-3-70919371-6_25, indexed in Pubmed: 7717128.

34. Sitathanee C, Dhanachai M, Poonyathalang A, et al. Stereotactic radiation therapy for optic nerve sheath meningioma; an experience at Ramathibodi Hospital. J Med Assoc Thai. 2006; 89(10): 1665-1669, indexed in Pubmed: 17128842.

35. Smith JL, Vuksanovic MM, Yates BM, et al. Radiation therapy for primary optic nerve meningiomas. J Clin Neuroophthalmol. 1981; 1(2): 85-99, indexed in Pubmed: 6213657.

36. Turbin RE, Thompson CR, Kennerdell JS, et al. A long-term visual outcome comparison in patients with optic nerve sheath meningioma managed with observation, surgery, radiotherapy, or surgery and radiotherapy. Ophthalmology. 2002; 109(5): 890-9; discussion 899, indexed in Pubmed: 11986093. 